\title{
IMPROVING SSTI FOR INNOVATIVE ECONOMIC DEVELOPMENT: EXPERIENCE OF BELARUS
}

\author{
Sergey V. Makarevich \\ Belarusian state university, Faculty of Economics, Minsk, Belarus
}

CMESTE

JEL Category: 011

\begin{abstract}
The development of the state system of scientific and technical information of the Republic of Belarus (SSTI) in the context of the modern world trends, such as the transition of countries to the innovative economy, an increase in the volume of information exchange at the international level, liberalization of access to the results of scientific research, development of the Internet and IT-technologies, etc., is considered in the current article. The author observes the peculiarities of the development of the foreign scientific and technical information systems appealing to the decentralized STI systems in the United States of America, Germany, France, and Finland. A special emphasis is given to the history, prerequisites of its origin, organizational structure, and principles of the state system of scientific and technical information of the Republic of Belarus, which at the present stage is a growing and disordered set of resources with variable structures, themes, and functionalities. The article demonstrates advantages and disadvantages that are characteristic of the current stage of development of this system in the Republic of Belarus, and also lists some main directions in which it is planned to develop the SSTI of the Republic of Belarus to compose a single republican and world digital information space and to provide consumers with the scientific and technical information required in the context of the development of an innovative economy.
\end{abstract}

Keywords: state system, scientific information, technical information, digital economy, information centers, development trends

\section{INTRODUCTION}

The management of information resources and information flows in the scientific and technical areas plays an important role in the innovative development of the country. In its turn, the functioning of an innovative economy is not possible without the use of an effective state

Address of the author:

Sergey Makarevich

莑; maksertex@tut.by system of scientific and technical information (hereinafter - SSTI), designed, on the one hand, to provide the needs of scientists, engineers and technicians, managers and students in scientific and technical information (hereinafter - STI), and on the other hand, to present national scientific and technical products at the global information market.

The State System of Scientific and Technical Information (SSTI), currently operating in the Republic of Belarus, on the one hand, has inherited many components and principles of 
operation from SSTI of the former USSR. On the other hand, the transformation of the system was influenced by the economic and administrative reforms that began in the Republic of Belarus in the early 1990s, as well as the revolutionary changes in information technologies that led to the emergence of the Internet and the development of IT technologies. Significant improvements are required in the current SSTI of the Republic of Belarus for ensuring the innovative development of the country's economy.

To identify possible areas for improvement, it is necessary to identify the main trends in the context of which this development is carried out and to analyze the inconsistencies and development bottlenecks in the state system of scientific and technical information of the Republic of Belarus.

The problems of the functioning and development of the SSTI of the Republic of Belarus at the present stage are reflected in the works of Grigyants R.N (Grigyanets R., at al., 2016), Enin S.V. (2017), Kosovsky A.A. (2017), Ugrinovich E.V. (Ugrinovich E., at al., 2017), Shumilin A.G. (2017) and other researchers.

\section{EXPERIENCE IN THE SSTIS DEVELOPMENT}

Decentralized STI systems operate in many western countries. The main component of such systems is a multifunctional information center. The internal organization and structure of information centers are aimed at the effective accumulation and processing, transferring of information to industrial enterprises, firms, and institutions to ensure an innovative economy. To improve aggregation, processing, and translation of information, the centers are equipped with modern information systems that enable the digitization, storage, and processing of large amounts of information, as well as automated information search.

The main sources of information for such centers, as a rule, are research institutes, universities, libraries, research funds, government agencies, and other organizations of both national and international levels.

An example is the activities of The US National Technical Information Service (NTIS). This body was established after the Second World War and was designed to accumulate STI, and is publically funded. NTIS currently stores more than 3 million units of documents in 350 industries, 600 thousand of which are available online. Access to information is provided to companies for some fee, but this type of activity is just a small part of the Center's income. The Center receives the main financial returns from related services in the field of information and communication technologies. The Center is currently reviewing its package of services, considering initiatives to disseminate open access and open data

Since 1970, a system of centers of technical information (Fachinformationszentrum - FIZ). has been operating in Germany. It includes such wellknown scientific and information centers as " $\mathrm{FIZ}$ Chemie", "FIZ Technik", "FIZ Karlsruhe (Energie, Physik, Mathematik)" and others. Taking into account modern requirements, in 2002 the German Federal Ministry of Education and Science, as well as the German Research Foundation supported a project to integrate distributed electronic resources of information centers, scientific and technical libraries, universities, research institutes in Germany, as well as to provide wide access to full texts in a single interface based on modern search methods. Initially, the project was designed as a part of the Vascoda scientific portal. The portal aggregated the resources of STI organizations, that have united in an association in Germany, including those resources that are located on the deep web.

In 2011, the information resources of the Vascoda consortium members were integrated into the WorldWide Science international resource portal, which appeared on the network in 2007 on the initiative of the British Library and the US Department of Energy. Currently, this portal is represented by more than 100 national and international scientific databases from 70 countries, providing the possibility to search in the deep web and automatically translate into 10 of the most common languages.

France's largest Center for Scientific and Technical Information (INIST) maintains a scientific portal and generates databases, including large ones such as the Francis database, which was founded in 1972 and contains 2.6 million records in 15 disciplines, as 
well as Pascal abstract database, which includes 20 million links and has been maintained in 1973 . In addition to providing access to databases, the portal possesses services for translating articles into English, promoting publications, scientometric measurements for scientists, assigning digital object identifier (DOI), etc. The system contains more than 700 thousand entries. The portal also offers its users the capabilities of the OpenGrey system, which specializes in grey literature published in Europe. The system allows to export records and finds documents that are poorly indexed by virtual search engines.

A special emphasis should be given to VTT - the Finnish center for technical research. "Here, we managed to create one of the most effective transfer models of ready-made high-tech solutions for business in the field of energy, ecology, and infrastructure".

The current stage of development of STI systems is characterized by the following phenomena:

- the transition from print to electronic versions of scientific literature.

- creation of thematic electronic libraries and storage of digital objects of general access.

- dissemination of open, free access to scientific publications.

- publication of row data from experimental studies.

- creation of educational information resources.

- constant access via the Internet to scientific publications using DOI and a standard set of metadata (Dublin Core) describing a digital object.

- development of the technological base of STI systems using specialized computer networks and cloud technologies.

- usage of artificial intelligence systems for the search and analysis of STI.

The following main world trends that determine the development of national STI systems at the present stage can be distinguished:

- the transition of many countries to innovative economic development. The core, ensuring the innovative development of the national economy, is the national innovation system, which proves to be non-viable without an effective STI system.
- an increase in the volume of information exchange on an international scale. The acceleration of the generation of new knowledge and the growth of its role in socioeconomic progress are accompanied by an increase in the exchange of information worldwide.

- liberalization of access to research results for all categories of users. In particular, the concept of Open Science is being further disseminated and developed.

- the development of the Internet and ITtechnologies. The development of the Internet and IT technologies in many countries, has resulted in the formation of a single information and research space, providing access to the allocated resources of STI.

\section{CURRENT STATE OF SSTI IN THE REPUBLIC OF BELARUS}

The currently functioning SSTI of the Republic of Belarus, which was formed in the 1960-1980s, has inherited many components and operational principles from the SSTI of the former USSR. The organizational principles of this system corresponded to the management structure of the national economy with appropriate subsystems organized by territory and industry, as well as specialized by types of documents and topics of information services. It was organized according to the principle of centralized processing and decentralized use of STI. A distinctive feature of the system was the hierarchically structured algorithm of processing published and unpublished national and foreign documentary STI sources based on the principles of single entry and processing of the information, that they contain, in institutes, libraries, archives, enterprises. An effective system of access for specialists to almost all sources of open information was formed, regardless of their storage location.

Economic and administrative reforms in the Republic of Belarus at the beginning of the 1990s. coincided with the revolutionary changes in information technology that led to the emergence of the Internet, the development of mobile communications, and personalization of access. As a result, many STI bodies were closed, others changed their profile. SSTI as an integral system 
has ceased to exist, although a number of its components continue to function at present.

Today in Belarus, the state system of scientific and technical information unites many organizations whose main tasks are to ensure the formation and effective use of scientific and technical information resources, their integration into the global information space, and the promotion of the creation of a market for information products and services.

The following bodies operate within the SSTI of the Republic of Belarus:

- republican information centers.

- libraries.

- industry centers and STI services.

- regional centers of STI.

- the system of publication and distribution of scientific and technical literature.

- information and telecommunication infrastructure.

Republican information centers are simultaneously inter-sectoral information centers:

- State Organization "Belarusian Institute of System Analysis and Information Support for Scientific and Technical Sphere" (SO "BELISA") is responsible for unpublished documents (reports on research, development, and experimentaltechnological works and deposited manuscripts).

- RPRUE "Belarusian State Institute of Standardization and Certification" is responsible for technical normative legal acts in the field of technical regulation and standardization.

- State Institution "National Center for Intellectual Property" is responsible for patent information.

The functioning of SSTI is complemented by the emergence and development of non-state systems of STI. A certain amount of local STI resources is generated by individual scientific institutions, university departments, individual scientists, also in social networks.

As a result of the development of the Internet, Belarusian users have access to foreign STI systems. In particular, scientific, educational, and budgetary organizations have the opportunity to access global computer networks via the Pan-
European GEANT network, which unites 40 million users from more than 8 thousand research and educational organizations from 40 European countries. Among Russian resources, the Scientific Electronic Library, Cyberleninka, Integrum can be singled out.

To develop the interstate exchange of scientific and technical information, the Republic of Belarus cooperates with the Interstate Council on Coordination in the Sphere of Scientific-Technical Information and Innovation (ICCSTI) and the International Center for Scientific and Technical Information (ICSTI). ICCSTI is one of the bodies of the Commonwealth of the Independent States responsible for the development of the interstate exchange of scientific and technical information. ICSTI is an interstate organization, the main task of which is to provide informational, analytical, consulting, and organizational support for cooperation in the field of science, technology, and business at the international level.

It should also be noted that in the context of global trends, new information technologies, including semantic technologies, big data, artificial intelligence, machine learning, are developing and finding applications in the Republic of Belarus.

As a result, the SSTI currently represents a growing and disordered set of resources having various structures, themes, and functional purposes. Attempts to integrate STI resources are non-systemic.

The following disadvantages of the SSTI of the Republic of Belarus at the current stage can be singled out:

- low degree of integration in the system. To date, the SSTI of the Republic of Belarus does not function, it contains an unordered set of resources, serving mainly the interests of various departments to which these resources belong.

- low degree of optimization in the system. The system of SSTI of the Republic of Belarus in its current state is not optimized to meeting the needs of the innovative economy in the Republic of Belarus. It does not provide mechanisms for tracking the full life cycle of innovative developments. There is no mechanism for information support of the process of commercialization of the results of R\&D. 
- There are some deficiencies in managing the development of the system. To date, there is no state-approved SSTI development strategy that would contain an evidencebased understanding of the future use of the SSTI of the Republic of Belarus.

- The system has a low degree of digitalization. The SSTI of the Republic of Belarus is characterized by the insufficient application of modern IT technologies in comparison with other countries.

- insufficient degree of integration with other countries' STI systems. The exchange of the results of scientific activities of the Republic of Belarus at the international level is unsystematic.

\section{DIRECTIONS OF SSTI IMPROVING TO ENSURE THE INNOVATIVE DEVELOPMENT OF THE REPUBLIC OF BELARUS}

An increased role of knowledge in socio-economic progress, an enlarged volume of information exchange on an international scale, and the transition of the Republic of Belarus to the digital economy have led to new requirements for the STI quality. To meet the requirements imposed by current world trends and to provide consumers with the STI required, the State Scientific and Technical Institute of the Republic of Belarus needs to be improved in some basic directions:

- The SSTI should ensure the maximum possible coverage of the STI created in the world, primarily in lead countries in areas of scientific, technological, and innovative development, and should provide users in the Republic of Belarus with the access to the world resources of STI.

- The SSTI should ensure the maximum possible coverage of the STI created in the Republic of Belarus, including $100 \%$ coverage of the results of scientific and technical activities publicly funded.

- The SSTI should provide effective information support for promoting the results of scientific, technical, and innovative activities of the Republic of Belarus, for their transfer, commercialization, and their implementation in innovative technologies, goods, and services.
- The SSTI should provide users with the possibility to search for information about scientific, technical and innovative activities results based on user-specific search parameters, specific areas of scientific and technological development, variable sectors of the economy, etc. and to distinguish these results taking into account the stages of the innovation life cycle (from concept, idea through basic research, applied research to launching innovative technology of goods, services to the market).

- The system should provide collection, accumulation, processing, search, and provision of information based on the principle of centralized one-time processing of the global information flow of documents in the area of science and technology and its multiple uses by consumers via the Internet.

- The system should provide effective navigation of users through information resources using a user-friendly interface and provide information to the end-user in the most convenient form, as systematic and detailed as possible, even though this information can be extracted from heterogeneous sources. The system should combine. access to all types of STI in a single interface - electronic and conventional library funds, depositories, archives, combine and systematize information from geographically distributed resources.

- The system should provide automation of technological processes for collecting, processing STI, and the formation of electronic resources using automated software implementation.

- The integration of the SSTI of the Republic of Belarus with the STI systems of other countries should be ensured at the national level.

For the SSTI to be able to fulfill the abovementioned requirements, some technical and economic measures are necessary. Soon, the following activities can be implemented:

1. Creation of an automated system for collecting and processing information about events, research and studies on the development of the state system of scientific and technical information will be aimed at eliminating the existing problematic aspects 
in the field of SSTI, improving the quality of data processing and more efficient analysis of the activities of public administration, improved monitoring.

2. The creation of the Office of Commercial Proposals, first of all, is aimed at using the already existing research and development results presented in the State Register of R\&D. Taking into account the world experience of such activities, the office's tasks will include copyright regulation, activities in the field of patenting and licensing of scientific and technical activities, communication with potential exploiters of scientific and technical products, implementation of activities for transfer, use of new knowledge, technologies, products, services, manufacturing, and public sectors. The office should be a kind of a bridge between science, business, government, and industry.

The office must perform the following tasks:

- analysis of patentability of technical solutions to define the chances of patent obtaining.

- preparation and support of applications for patents of all types of intellectual property.

- preparation and maintenance of applications for registration of computer programs in the Copyright Office of the Library of Congress and the countries of the Berne Convention.

- establishing a fund of patented national intellectual property objects.

- conducting patent analytics using the analysis of the above-mentioned fund of patent documents.

- analysis of the data available in the State Register of R\&D.

- support of negotiations of the parties on the issues of commercialization of R\&D.

- preparation of agreements on the creation and disposal of intellectual property rights (license agreements, agreements on the alienation of exclusive rights, copyright contracts, $R \& D$ contracts, etc.).

3. Modernization of epy State Register of $R \& D$ which will allow providing effective information support for promoting the results of scientific, technical, and innovative activities created in the Republic of Belarus, support for their transfer, commercialization, their implementation in innovative technologies, goods, services.

4. Optimization of the costs of maintaining the server infrastructure of scientific and technical libraries by accumulating stored information in the cloud and storing backups from the delegated body.

The SSSTI system contains 5 libraries that have their electronic resources and databases, as well as their server capacities for their storage.

When deploying information resources on cloud services, one of the ways to utilize (use) the freedup server equipment may be to accumulate it in a single place for creating backup copies, which will save space on rented disk space and money.

\section{CONCLUSION}

Today, the most important national priorities of economically developed countries include the creation of an effective national innovation system (NIS) that ensures the competitiveness of the national economy in the context of globalization, and the creation of a lifelong education system that ensures the reproduction of "human capital", capable to generate, perceive and implement innovations. It seems to be impossible to solve these problems having no effective state system of scientific and technical information

While decentralized STI systems operate in many Western countries, a centralized-structured STI system is presented at the national level in such countries as the Republic of Belarus, the Russian Federation, and in several other countries of the post-Soviet space. The following global trends had a decisive influence on the development of the STI system in the world and the Republic of Belarus: the transition of countries to the innovative economy, an increase in the volume of information exchange at the international level, liberalization of access to the results of scientific research, the development of the Internet and IT technologies.

The National Innovation System of the Republic of Belarus follows current global trends, striving to create a single republican and global information and digital space. Moreover, the SSTI should, first and foremost, provide effective informational support for promoting the results of scientific, technical, and innovative activities of the Republic of Belarus. 


\section{WORKS CITED}

Grigyanets, R., Lapitsky, V., Tuzikov, A., Naumenko, D., \& Wenger, V. (2016). Scientific and methodological support for the development of informatization and the state system of scientific and technical information of the National Academy of Sciences of Belarus in 2016. The development of informatization and the state system of scientific and technical information RINITI 2016: Reports of the XV International Conference, 40-46.

Kosovsky, A. (2017). Perspective direction of development of the system of scientific and technical information in the Republic of Belarus. Development of Informatization and the State System of Scientific and Technical Information RINITI 2017: Reports of the XVI International Conference, 6-9.

Shumilin, A. (2016). On promising scientific, technical and innovative development of the Republic of Belarus (state, problems, solutions). System "science - technology - innovation": methodology, experience, prospects: materials of the International Conference, 4-12.

Ugrinovich, E., Moon, D., \& Peteta, D. (2017). Overcoming negative trends, threats, and risks in the process of forming the international information infrastructure of science and education. System "science - technology - innovation" methodology, experience, prospects: materials of the International scientific-practical conference, 54-64.

Yenin, S. (2017). On the digital transformation of public administration in the Republic of Belarus. Development of Informatization and the State System of Scientific and Technical Information RINITI 2017: Reports of the XVI International Conference, 35-41.

Received for publication:

11.03 .2020

Revision received:

10.05 .2020

Accepted for publication:

01.07 .2020

\section{How to cite this article?}

Style - APA Sixth Edition:

Makarevich, S. V. (2020, July 15). Improving SSTI for innovative economic development: Experience of Belarus. (Z. Cekerevac, Ed.) MEST Journal, 8(2), 130-136. doi:10.12709/mest.08.08.02.14

Style - Chicago Sixteenth Edition:

Makarevich, Sergey V. 2020. "Improving SSTI for innovative economic development: Experience of Belarus." Edited by Zoran Cekerevac. MEST Journal (MESTE) 8 (2): 130-136. doi:10.12709/mest.08.08.02.14.

Style - GOST Name Sort:

Makarevich Sergey V. Improving SSTI for innovative economic development: Experience of Belarus [Journal] // MEST Journal / ed. Cekerevac Zoran. - Belgrade - Toronto : MESTE, July 15, 2020. - 2 : Vol. 8. - pp. 130-136.

Style - Harvard Anglia:

Makarevich, S. V., 2020. Improving SSTI for innovative economic development: Experience of Belarus. MEST Journal, 15 July, 8(2), pp. 130-136.

Style - ISO 690 Numerical Reference:

Improving SSTI for innovative economic development: Experience of Belarus. Makarevich, Sergey V. [ed.] Zoran Cekerevac. 2, Belgrade - Toronto : MESTE, July 15, 2020, MEST Journal, Vol. 8, pp. 130136. 